\title{
Biological Clearance Rate
}

National Cancer Institute

\section{Source}

National Cancer Institute. Biological Clearance Rate. NCI Thesaurus. Code C70914.

The rate at which an exogenous substance is removed or cleared from the whole or part of the body. 